herbal coolant was also very prominent among them, such as jal jeera, mint, cucumber, onion garlic, lemon water, curd, etc., as these coolants were easily available to farmers. With reference to clothing habit wearing loose cloth was only adopted by 47 percent. The data regarding the protective methods to be adopted while performing the farm activities, it was revealed that sunglass, hat, gloves, umbrella scarf etc. were least adopted by them due to their poor feasibility while performing the task.

Conclusion Thus, with the pace with which global average temperature is rising, emergency preparedness is very important among outdoor workers in order to keep themselves protected from heat stress. Creating awareness and developing PPE to safeguard is important.

\section{THE ENVIRONMENT AND HEALTH}

John Gallagher. Consultant in Occupational Medicine and Adjunct Professor College of Medicine and Health, University College Cork, Cork, Ireland

\subsection{6/oemed-2018-ICOHabstracts.313}

Aim This session looks at the environment and the workplace as contiguous entities and as such having many shared influences.

${ }^{1}$ DAM Hogan, ${ }^{1}$ Fiona Geaney, ${ }^{2}$ Stig Hellebust, ${ }^{3}$ BA Greiner

${ }^{1}$ School of Public Health, University College Cork, Cork, Ireland

${ }^{2}$ Centre for Research into Atmospheric Chemistry, School of Chemistry and Environmental Research Institute, University College Cork, Cork

${ }^{3}$ School of Public Health, University College Cork, Cork, Ireland

\section{8a WORK RELATED MUSCULOSKELETAL DISORDERS, PHYSICAL WORK FACTORS AND PSYCHOSOCIAL WORK FACTORS FOR CHARTERED PHYSIOTHERAPISTS, PHYSICAL THERAPISTS AND ATHLETIC THERAPISTS IN IRELAND}

DAM Hogan*, S Nolan, BA Greiner. School of Public Health, University College Cork, Cork, Ireland

\subsection{6/oemed-2018-ICOHabstracts.314}

Introduction In the epidemiological literature, physical exposure and psychosocial work factors are now recognised as major contributing work environmental factors for workrelated musculoskeletal disorders (WRMSDs). Healthcare workers such as physiotherapists and physical/athletic therapists are exposed to risk factors for WRMSDs on a daily basis, despite having specialist knowledge of body mechanics and injury prevention strategies.

Methods A cross-sectional study 'Health in Hand-Intensive Tasks and Safety' (HITS). Study sample consisted of 347 employed and self-employed practising therapists in Ireland. Postal questionnaires included questions about WRMSD symptoms, physical work risk factors, psychosocial and work organisational risk factors, among others. Analyses included logistic regression modelling.

Results 55.4\% reported that they had experienced WRMSD that lasted for more than 3 days in the past 12 months. The highest physical effort perceived was repetitive thumb movements (mean=5.08) and the lowest was bending the elbows (mean=3.5). Many affected therapists classified the following physical work factors as 'majorly significant' in negatively contributing to their musculoskeletal health, the repetitiveness of work motions $(54.6 \%)$ and high quantitative workload due to treating many patients/clients $(49.7 \%)$. In relation to psychosocial work factors, most therapists scheduled their appointments themselves $(65.7 \%)$. The odds of upper limb symptoms more than doubled $(\mathrm{OR}=2.3,95 \% \mathrm{CI})$ for those not booking their appointments. Social support emerged as an important issue for both the 12 month prevalence of any upper limb symptom and the prevalence of incapacitating symptoms. The level of self-reported influence at work and predictability of work were significantly associated with incapacitating symptoms after adjustment for confounders.

Conclusion The results suggest that therapist input into scheduling of clients/patients and supervisory support may be crucial to their musculoskeletal health. For employed therapists, social support is provided from colleagues and direct supervisors, however, for self-employed therapists social support has to take other forms, through the professional bodies and other organisations.

\section{8b THE FOOD CHOICE AT WORK TRIAL: FROM EVALUATION TO COMMERCIALISATION AND PRACTICAL APPLICATION IN EVERYDAY WORKPLACE SETTINGS}

F Geaney*. School of Public Health, University College Cork, Ireland and Food Choice at Work Ltd Cork, Ireland

\subsection{6/oemed-2018-ICOHabstracts.315}

Introduction The surrounding environments in which individuals live and work influences their health behaviours. Macro and micro-level modification of these environments is an important catalyst for behaviour change. However, evidence on effective workplace dietary interventions is limited. The FCW trial assessed the comparative effectiveness of a workplace dietary intervention involving nutrition education and system-level dietary modification both alone and in combination versus a control workplace on employees' dietary intakes, nutrition knowledge and health status. An economic evaluation assessed the cost-effectiveness of the FCW intervention from the perspective of healthcare providers in terms of QALYs and employers in terms of monetary benefits (reduced absenteeism).

Methods Four manufacturing workplaces in Ireland were allocated to control, nutrition education (Education), system-level dietary modification (System-level) and nutrition education and system-level dietary modification (Combined). Nutrition education included group presentations, individual consultations and detailed nutrition information. System-level dietary modification included menu modification, fruit price discounts, strategic positioning of healthier alternatives and portion size control. Data on dietary intakes, nutrition knowledge, health status, QALYs and absenteeism were obtained at baseline and at 7-9 months follow-up. Multivariate analysis of covariance compared changes across the groups. The economic evaluation included cost-utility and cost-benefit analyses.

Results Follow-up data were obtained for 541 employees (1864 years) (64\% of 850 recruited). There were significant positive changes in intakes of saturated fat $(p=0.013)$, salt $(p=0.010)$ and nutrition knowledge $(p=0.034)$ between baseline and follow-up in the combined intervention versus the control. Significant changes in BMI $\left(-1.2 \mathrm{~kg} / \mathrm{m}^{2} \quad(p=0.047)\right.$ were also observed in the combined intervention. System-level 
modification yielded the highest additional QALYs $(€ 101.37 /$ QALY) and annual net benefit for employers ( $€ 56.56 /$ employee).

Discussion Combining nutrition education and system-level dietary modification is an effective approach for promoting healthy eating at work. The FCW intervention is a sustainable cost-effective model and wide-scale implementation is underway at local and national workplaces.

\section{C PARTICLES AT WORK - AND EVERYWHERE ELSE}

Stig Hellebust*, John Wenger, John Sodeau. Centre for Research into Atmospheric Chemistry, School of Chemistry and Environmental Research Institute, University College Cork, Cork

\subsection{6/oemed-2018-ICOHabstracts.316}

Airborne Particulate Matter (PM) is ubiquitous in both indoor and outdoor environments. Its adverse effect on human health is well known and is associated with both size and composition of particles. PM is a complex and heterogenous mixture, including a range of both toxic and non-toxic chemical compounds. These materials can penetrate in the human respiratory tract with the possibility to cause respiratory and heart related illnesses.

Small particulate pollution has health impacts even at very low concentrations - no threshold has been identified below which no damage to health is observed. WHO estimates that in 2012 around 1 in 8 deaths were attributed to exposure to air pollution, making it the number one environmental risk factor for ill health.

Particulate matter (PM) constitute a principal component of residential indoor air pollution and have been linked with both acute effects, such as irritation in the skin, eyes, nose and throat and upper airways, and chronic health effects including asthma and cardiac disease. It is also of concern in many workplace environments across a wide range of industries and sectors. Wood dust, especially hardwood dust, has been known to cause health problems and cancers in workers. Aerosols from cleaning spray products pose a threat to cleaning workers. In the ceramic sector workers can be exposed to a wide variety of powdered materials with different characteristics and chemical compositions during the manufacturing cycle (handling, materials preparation, bag filling, tiles production or cleaning processes, among others). Cooking aerosols are emitted in high concentrations from processes like frying and charbroiling, exposing kitchen and restaurant workers to high levels of airborne organic aerosols. Nanoparticles is a relatively new and little understood threat to both manufacturing and laboratory workers, and it is not known how many escape to the wider environment. Any workshop environment may contain high levels of particles in the indoor air, as will construction environments, where workers may potentially be exposed to a range of materials, including asbestos particles. Even office workers occupying near-road premises can experience high levels of toxic particles from vehicle emissions.

Furthermore, bioaerosols are a class of atmospheric particles that include bacteria, viruses, pollen and fungal spores, algae, plant debris, proteins, etc. This class of particles can also have an impact on public health, as they have been associated with infectious diseases, allergies, acute toxic effects and even cancer.

\section{8d THE PSYCHOSOCIAL WORK ENVIRONMENT, SUICIDE AND SELF-HARM: RESULTS FROM A CASE CONTROL STUDY}

BA Greiner*, S Leitao, C Larkin, P Corcoran, J Gallagher, E Arensman. School of Public Health, University College Cork, Cork, Ireland

\subsection{6/oemed-2018-ICOHabstracts.317}

Introduction Research shows that suicides are more common among the unemployed and in certain occupations such as elementary occupations, agriculture, construction and health care. Little is known about the specific psychosocial determinants in the occupational environment.

Methods A case-control study using psychological autopsy method with multiple sources including information from coroners' reports, GPs and next-of-kin interviews in 133 consecutive cases of suicide and probable suicide compared with frequency-matched general practice controls $(n=53)$. Psychosocial work factors encompassed decision latitude, work demands, job insecurity social support and social relations. $\mathrm{Chi}^{2}$ and logistic regression modelling with adjustment for confounders and comparison with Central Statistics Office employment data.

Results Of the 133 cases, 22\% had worked in construction and $30 \%$ were unemployed, an overrepresentation when compared to national employment data. Of those unemployed, $36 \%$ had worked in construction. Cases were more likely to be unemployed $(11 \%$ versus $6 \%)$ than controls and have worked in construction (29\% versus 17\%) and in agricultural/ fisheries (14\% versus 6\%). Controls had a significantly higher job decision latitude, higher social support and higher job security compared to cases. Additional comparisons with adjustment for confounding will be presented.

Discussion The results concerning decision latitude are in line with other research showing that workers in elementary jobs are more prone to suicide. The Irish construction sector has been highly affected by the recent economic recession with many layoffs and insecure jobs. The overrepresentation of this sector in the suicide cases and the finding of job insecurity being associated with suicide suggests that job loss but also the threat of job loss may be a precipitating factor to suicide. The results will inform Ireland's National strategy to reduce suicide 'Connecting for Life', which specifically highlights that prevention approaches should target priority groups, one of them being specific occupational groups.

\section{WORLD TRADE CENTRE RESEARCH STRATEGIES, IMPLICATIONS AND FINDINGS}

Rafael E de la Hoz. Icahn School of Medicine at Mount Sinai, New York, NY, USA

\subsection{6/oemed-2018-ICOHabstracts.318}

Aim of special session The World Trade Centre research enterprise posed particular logistical and strategical challenges, and its research findings have made contribution to occupational health and the understanding of respiratory health and chronic airway disease. All of those aspects will be discussed in this session.

${ }^{1}$ Philip J. Landrigan, MD, MS, DIH, ${ }^{1}$ Roberto G. Lucchini, MD, ${ }^{2}$ Laurie Breyer, JD, MA, ${ }^{2}$ Dr. Max Lum, Ed.D, MPA, ${ }^{1}$ Rafael E. de la Hoz, MD, MPH, MSc 